\title{
A experiência da dor em bailarinas clássicas: significados emergentes num estudo qualitativo
}

\author{
The experience of pain among classical dance ballerinas: meanings \\ derived from a qualitative study
}

Cátia Costa (https://orcid.org/0000-0001-7130-6283) ${ }^{1}$

Zélia Teixeira (https://orcid.org/0000-0001-8422-5239) ${ }^{1}$

${ }^{1}$ Faculdade de Ciências

Humanas e Sociais,

Universidade Fernando Pessoa. Pç. 9 de Abril 349. 4249-004 Porto Portugal. cc_catia@hotmail.com

\begin{abstract}
This article presents the results of a study focused on the meaning that pain assumes in the discourse of a group of classical dance ballerinas. To achieve this, we accessed their experiences and perceptions through a semi-structured interview, to better understand the pain that is an integral part of their routines before, during and after a performance. This study is based on the discourses which emerged from a group of ten ballerinas with six or more years of training, and the method chosen to tap into the underlying meanings was Grounded Analysis or Sustained Data Analysis. The analysis of the discourses collected revealed that pursuing a dancing career involves obstacles that increase the demands felt by the ballerinas, in parallel with their desire to remain in the world of performance. Thus, it is the excessive practicing and repetitive movements which give rise to pain and injuries, which are concealed and denied so as not to impede the focus of attaining perfection. In general, the results obtained emphasize the passion for dance that involves pain as an ally to this career and force the ballerinas to varied confrontation strategies. In tandem, pain is linked to fear of injury, to the end of a career as a ballerina and the relinquishment of a dream.
\end{abstract}

Key words Dance, Pain, Injury, Grounded analysis
Resumo Este artigo apresenta os resultados de um estudo centrado no significado que a dor assume no discurso de um grupo de bailarinas de dança clássica. Para tal acedemos às suas experiências e vivências através de uma entrevista semiestruturada de forma a entender a dor que faz parte suas rotinas antes, durante e após estarem a dançar. O estudo sustenta-se nos discursos que emergiram num grupo de dez bailarinas, com mais de seis anos de formação, e o método para aceder aos significados providenciados pelas suas vozes foi a "Grounded Analysis" ou Análise Sustentada nos Dados. A análise dos discursos recolhidos revelou que o evoluir no percurso da dança implica dificuldades que aumentam as exigências experienciadas pelas bailarinas, paralelamente ao desejo de querer permanecer no mundo do espetáculo. Assim são os treinos excessivos e os movimentos repetitivos que fazem surgir a dor e as lesões, que são ocultadas, negadas, de modo a poder continuar no foco de querer alcançar a perfeição. Em geral, os resultados obtidos salientam a paixão pela dança que configura a dor como aliada desta prática, e obriga as bailarinas a várias estratégias de confronto. Paralelamente, a dor liga-se ao medo da lesão, ao fim do percurso como bailarina e ao abdicar de um sonho.

Palavras-chave Dança, Dor, Lesão, Grounded Analysis 


\section{Introdução}

A dança é uma arte complexa cujo instrumento de expressão é o corpo que se desenvolve com o intuito da perfeição da técnica artística. Por isso é tão necessário cuidar da qualidade e da sustentabilidade física e psicológica dos bailarinos ${ }^{1}$.

A rotina diária altamente competitiva das aulas e ensaios é incorporada pelos bailarinos como essencial para o seu desempenho, porque só assim é que lhes é permitido adquirir a extraordinária força, resistência, velocidade, flexibilidade, equilíbrio e controle, base para a aquisição de uma carreira no mundo da dançá2.

Os movimentos graciosos e os sorrisos que são vistos pelo público estão mascarados por longas horas de treino intensivo, dores e lesões. Os bailarinos desempenham funções extremamente exigentes, sobretudo a nível da capacidade e força física. Neste registro de exigência, o contexto em que estão inseridos reflete-se num forte estresse, pois exige preparação para a execução nos diversos repertórios de novos movimentos ${ }^{3}$. Deste modo explica-se a intensa rotina de trabalho vivenciada pelos elementos que integram companhias de dança profissionais, com extensas cargas horárias, a par de expectativas incertas quanto à futura carreira ${ }^{4}$.

O ballet clássico é uma atividade que exige uma alta performance e um alto nível técnico ${ }^{5}$. Desta forma parece ser consensual que, quer a formação quer a prática profissional de bailarinas de dança clássica, implicam grande esforço físico, frequentemente associado à dor.

Sendo a dor considerada como uma experiência desagradável que decorre de um estímulo lesivo ao organismo, que o ser humano controla e a que reage de forma particular e de diferentes formas, é difícil definir esta vivência 5 .

A experiência dolorosa pode estar relacionada com o treino em si como parte integrante da preparação física, mas também com as lesões que ocorrem acidentalmente no percurso de quem dança ${ }^{5}$. Este pode ser o lado negro de uma prática performativa que pressupõe uma demonstração de beleza estética aparentemente sem esforço, de forma tão perfeita que consiga provocar emoções no público 5 .

Uma das problemáticas confirmadas desta prática é a ocorrência de lesões que conduzem a consequências muito negativas para a saúde dos bailarinos. Prejudicam os treinos, a sua performance e o desenvolvimento do seu percurso como bailarinos, sendo preocupações omnipresentes que nem sempre têm uma correta intervenção ${ }^{6,7}$.
E se a literatura que se debruça sobre a dança como um texto passível de interpretação tem vindo a aumentar, não podemos dizer o mesmo dos estudos que se centram na experiência emocional dos bailarinos, nomeadamente no que diz respeito ao risco, à dor e às lesões inerentes à sua carreira que muitas vezes se sobrepõe com um estilo de vida específico ${ }^{1}$.

Encontramos vários estudos que referem que muitos bailarinos continuam a dançar mesmo estando magoados como forma de prevenir uma perda de parte da sua identidade enquanto bailarinos, uma vez que a dor, as lesões e a persistência fazem parte do mundo da dança ${ }^{6}$. São resultado de uma aprendizagem que também se faz olhando o exemplo dos outros profissionais mais evoluídos, originando desta forma dois vetores de pressão: internos e externos ${ }^{7}$. São raros os bailarinos que não se confrontam com as lesões e consequentemente com a dor durante o seu percurso artístico e profissional. Os estudos epidemiológicos apontam taxas de lesões entre os $55 \%$ e os $90 \%$ de executantes 8 . Nesta linha de investigação têm surgido evidências de que o treino excessivo e o consequente cansaço são condições associadas às lesões, na medida em que a maioria destas são de repetição, produto da manutenção do esforço em atividades e movimentos quando já existem lesões microscópicas 4 .

O medo de que possa ocorrer uma lesão e o processo de recuperação são aspectos que envolvem o foro psicológico e não devem ser negligenciados, e é pouco o que se sabe sobre a procura de tratamento por parte dos bailarinos 9 .

Para muitos estudantes e profissionais a dança é a componente central da sua identidade, com uma dedicação quase total para que consigam atingir níveis elevados de performance ${ }^{10}$, razão pela qual uma lesão grave, que invalide dançar, pode ter um efeito arrasador.

Como acima referimos a identidade do bailarino confunde-se com a dança, o que pode deverse à exigência e absorção da própria performance. Esta associa-se à perceção de que apenas um grupo privilegiado e específico é que pertence a este mundo, o que dificulta a possibilidade do envolvimento social fora do círculo artístico ${ }^{2}$.

Assim, numa cultura de entretenimento que está orientada essencialmente para a criação de uma técnica perfeita e para a visualização de um resultado esteticamente agradável e entusiástico, o conceito de risco não surge à primeira vista, neste mundo de tutus, sapatilhas de pontas, beleza e iluminação. Quando consideramos a dança como uma atividade de risco, referimo-nos 
essencialmente ao estilo de vida dos bailarinos que é extremamente exigente, e às consequências que constituem maior ameaça, tanto a nível físico como psicológico 5 .

É reconhecido que subcultura da dança clássica tem bem claras as suas orientações e regras de funcionamento, nomeadamente no que diz respeito ao entendimento e à vivência do sofrimento físico, pelo que pensamos ser uma questão de investigação pertinente trazer alguma luz às experiências subjetivas de bailarinas clássicas, $e$ às narrativas emergentes do seu papel enquanto personagens principais de uma forma de arte que se sobrepõe à exigência de muitos desportos de topo $^{5}$, e detalhar no presente artigo a emergência dos múltiplos significados que configuram a experiência da dor associada à vivência da dança ${ }^{7}$.

\section{Métodos}

As caraterísticas do trabalho a que nos propusemos o recurso a um design qualitativo. Nas suas bases históricas a investigação qualitativa é definida como uma forma de estudo da sociedade, em que o principal objetivo é centrar-se no modo como as pessoas interpretam e dão sentido às suas experiências e vivências. $\mathrm{O}$ termo qualitativo implica um destaque nas qualidades das entidades e nos processos e significados, valorizando a qualidade social construída através da realidade ${ }^{11}$.

O investigador qualitativo estuda os fenômenos no seu contexto natural, procurando interpretá-los através dos significados que as pessoas lhes atribuem. Requer a recolha de materiais que descrevem momentos da vida dos indivíduos que são interpretadas de forma a aumentar a compreensão dos temas em estudo ${ }^{11}$. Esta opção por um estudo qualitativo foi enquadrada pelo interesse na descrição e na compreensão do processo de experienciar a dor por parte de bailarinas clássicas, visando aceder à complexidade e diversidade da realidade em estudo, de forma contextualizada e enriquecida através dos significados que lhe são atribuídos pelos participantes, dando-lhes voz e valorizando a sua subjetividade ${ }^{7}$.

É reconhecida a transversalidade da aplicação da investigação qualitativa, mesmo em áreas em que não se constitui como a prática mais frequente $^{12}$. Para esta autora importa salientar a diversidade de métodos e de abordagens, a par do crescente tipo de dados que podem ser alvo de análise, e da diversificação dos meios de comunicação e de documentação da vida quer dos indivíduos quer dos contextos sociais que os envolvem.

Pollard-Smith e Thomson', elencaram algumas das aplicações dos estudos qualitativos no contexto da dança clássica, ressaltando a importância da compreensão da experiência do indivíduo quanto à sua dor, lesões e tratamentos no seu contexto social, bem como na descrição dos fatores determinantes das lesões, tais como o estigma, o impacto na identidade do bailarino, e o medo de ser mal entendido pelos profissionais de saúde.

O presente estudo teve como fim compreender quais as tonalidades que a dor apresenta associadas às vivências das bailarinas de dança clássica, assumindo as experiências subjetivas como foco do nosso interesse ${ }^{12}$. Dentro da investigação qualitativa a Grounded Theory inclui-se no conjunto de técnicas que visa reduzir grandes blocos de dados, e/ou simplificar a complexidade dos mesmos. As linhas de orientação dos procedimentos são rigorosas, embora flexíveis ${ }^{13}$, e pretendem, através de uma análise essencialmente indutiva dos dados, chegar a uma organização teórica sustentada na informação selecionada. A Grounded Theory implica um processo interativo de recolha e análise de dados que pode ocorrer em simultâneo, que analisa ações e processos mais do que procura estruturas, recorrendo a métodos comparativos. O processo é centrado no desenvolvimento de categorias indutivas que contribuem para a construção de novas referências teóricas, em vez de recorrer à aplicação de constructos já existentes ${ }^{13}$. Assim sustentados procedemos à recolha, registo, transcrição, organização, interpretação, estudo e construção hierarquizada da informação obtida.

O presente artigo congrega os dados obtidos a partir de duas questões extraídas de um guião mais alargado que visava aceder às vozes de um grupo de bailarinas de uma forma que nos permitisse construir significados em torno da experiência de se ser bailarina. Para o objetivo específico (e consequentemente de acordo com a questão de investigação que nos interessou) selecionamos duas questões relacionadas com a vivência da dor de jovens bailarinas clássicas que fazem da dança um dos organizadores da sua vida.

\section{Amostra (participantes)}

O grupo de participantes neste estudo foi selecionado pelo método de bola de neve, reunindo 10 bailarinas cujas idades variavam entre os 18 e os 27 anos. O grupo inicialmente considerado 
contemplava mais 3 bailarinas, mas pela saturação das categorias ficamos com 10 elementos. Seis das participantes tinham o $3^{\circ}$ ciclo de escolaridade e quatro tinham formação superior, duas delas na área da dança. A prática regular da dança oscila entre os 8 e os 22 anos. O tempo médio de dança por dia varia entre a 1 hora e as 8 horas. Os dados mais específicos relativos à experiência da dança estão patentes na Tabela 1.

\section{Instrumentos}

A recolha dos dados que sustentam o presente estudo decorreu primordialmente em contexto online tendo garantidos todos os procedimentos éticos necessários (avalizados pela Comissão de Ética da UFP). Para tal foram criados dois instrumentos específicos com o intuito da caracterização sociodemográfica das participantes, e da exploração da sua experiência pessoal enquanto bailarinas, com especial enfoque na associação dança/dor.

\section{Questionário de Caracterização Pessoal (socioprofissional)}

A criação deste questionário, que podia ser realizado quer online quer offline, pretendeu aceder a um conjunto de dados sociodemográficos e profissionais (idade, escolaridade, profissão, idade com que iniciou a prática da dança, número de anos de treino) das 10 bailarinas.

\section{Entrevista Online Semiestruturada (Guião)}

Como referido anteriormente, este artigo foi elaborado com base em duas questões selecionadas de um guião mais amplo constituído por um total de nove perguntas. Muito sucintamente, pretendeu-se conhecer o percurso destas jovens na dança clássica, as suas conceções sobre a vida de uma bailarina, e o impacto desta prática na sua própria vida quotidiana. A associação entre dor e dança foi explorada tentando conhecer em que condições surgia e permanecia a dor, o efeito na sua performance, quer fosse derivada do treino ou de lesões, e quais as estratégias usadas para lidar com o sofrimento físico.

Os discursos que suportam as descrições e as reflexões patentes no presente artigo centram-se na análise das unidades discursivas selecionadas e posteriormente categorizadas hierarquicamente das respostas obtidas nas questões No seu caso, como é que lida com a dor / desconforto fisico que pode estar presente no treino diário? e Como é que descreve a sua experiência de ser bailarino e ter que conviver com as lesões?.

\section{Procedimentos}

Como já expresso, a presente investigação decorreu predominantemente online. Dado o papel tão central que as tecnologias de informação ocupam no nosso quotidiano, torna-se necessário explorar se o ciberespaço, como todos os outros espaços gerados e utilizados por humanos, permite a existência de emoções dentro de si mesmo. Não há espaços humanos sem um contexto emocional ${ }^{14}$. Numerosas crises de confiança descobertas pelo mundo digital (manipulações no sector financeiro, vigilância do tráfego de dados, ou revelações de plágio e falsificação na investigação científica) parecem indicar que as relações de confiança estão fragilizadas neste contexto. No entanto, vários contributos parecem indicar que a Internet providencia igualmente meios para

Tabela 1. Caraterização do grupo de bailarinas em função do tipo de dança que iniciou, dos anos que dança e quantas horas dança em média por dia.

\begin{tabular}{|c|c|c|c|}
\hline & $\begin{array}{c}\text { Que tipo de dança iniciou a sua } \\
\text { prática }\end{array}$ & Há quantos anos dança & $\begin{array}{c}\text { Quantas horas dança em } \\
\text { média por dia }\end{array}$ \\
\hline S 1 & Ballet clássico & 14 anos & 1 hora \\
\hline $\mathrm{S} 2$ & Ballet clássico & 8 anos & 5 horas \\
\hline S 3 & Hip Hop (antes do ballet) & 11 anos & 4 horas \\
\hline S 4 & Ballet clássico & 16 anos & 1h30min. \\
\hline S 5 & Ballet clássico & 12 anos & 1 hora \\
\hline S 6 & Ballet clássico & 16 anos & 1 hora \\
\hline S 7 & Jazz (antes do ballet) & 17 anos & $4 / 5$ horas \\
\hline S 8 & Ballet clássico & 22 anos & 2 horas \\
\hline S 9 & Jazz (antes do ballet) & 8 anos & 8 horas \\
\hline S 10 & Hip Hop (antes do ballet) & 16 anos & 5 horas \\
\hline
\end{tabular}


fortalecer estas relações de confiança, e inclusivé substituí-la. Por este mesmo motivo, no que concerne à confiança num mundo digital, levantam-se questões não só sobre o risco, mas também sobre novas oportunidades eventualmente emergentes ${ }^{15}$. Assim, e face aos vários formatos que são utilizados nos dias de hoje para aceder aos aspetos relevantes das vidas dos indivíduos (vídeos, redes sociais, etc.) estamos perante um desafio para os investigadores, que encontram nestes formatos oportunidades de partilhar e aceder a fontes de informação e conhecimento, bem como de recolha de dados principalmente nas ciências sociais e do comportamento ${ }^{16}$.

Com base no método de amostragem por bola de neve o contacto com a primeira participante sugerida decorreu por e-mail, tendo-se a investigadora disponibilizado para a recolha dos dados presencialmente ou através do Messenger, procedimento replicado junto de todas as eventuais participantes. As dez bailarinas preferiram participar no estudo sendo entrevistadas em tempo real, mas por escrito, ou seja, utilizando a plataforma acima referida. Como garantia dos pressupostos éticos o questionário e a entrevista só tinham lugar após o envio e a devolução do consentimento informado assinado, por via digital. O questionário de caracterização socioprofissional era preenchido da mesma forma. As entrevistas foram desenvolvidas tendo como referência o guião mais alargado com 9 questões ficando o seu conteúdo automaticamente registado em texto escrito. Desta forma a globalidade dos discursos tanto da entrevistada, como do investigador ficaram disponíveis no histórico do Messenger, facilitando o acesso a tudo o que foi escrito por ambas as partes, e diminuindo o espaço para erros de compreensão ou mal entendidos.

O presente estudo assenta na análise das respostas às duas questões selecionadas e os discursos foram abordados com o intuito de fazer emergir a subjetividade, a diversidade e a multiplicidade de conteúdos que poderão dar outras perspetivas da associação, nem sempre linear entre a dor e a dança. A codificação foi feita pelas duas investigadoras/autoras baseada numa análise linha a linha dos discursos escritos, com o fim de encontrar repetições de ocorrências conceptuais e de identificar eventuais padrões nas experiências das bailarinas entrevistadas. Recorreu-se ao processo de memoing ${ }^{13}$ como forma de registo e discussão das categorias que foram emergindo, e que foram posteriormente categorizadas hierarquicamente (como sendo de segunda e de primeira ordem $)^{17}$.

\section{Resultados}

O processo de agregação das unidades discursivas em categorias de $2^{\mathrm{a}}$ ordem e de $1^{\mathrm{a}}$ ordem, que dão forma à organização da estrutura conceptual das respostas à questão No seu caso, como éque lida com a dor/ desconforto físico que pode estar presente no treino diário? encontra-se espelhado na Tabela 2.

De uma forma simplificada podemos dizer que a resposta à questão relacionada com a dor no treino diário construída pelo discurso do grupo seria: a dor é uma aliada da dança que se ignora e/ ou se ultrapassa, com estratégias associadas ao seu controle, e com frustração.

Mais especificamente, e passando desta visão global para a análise dos pormenores emergentes das respostas, verificámos que várias participantes perspetivam a dor como algo positivo e até como cúmplice da prática da dança clássica.

Assim, acedemos a um total de quatro categorias de $1^{\text {a }}$ ordem, das quais a que obtém mais relevo (pelo número de sujeitos e referências) é "A dor como aliada da dança clássica", em cuja construção podemos registar quatro categorias de 2a ordem: "Vê a dor como aliado", "A dor é interpretada de forma positiva", "Aceitação da dor" e a "Dor natural" que expressam uma perspetiva pacificada da experiência dolorosa.

Surgiram ainda outras duas formas de lidar com a dor referidas pelas 10 bailarinas como categorias centrais. A primeira, "A dor ignora-se e ultrapassa-se", é constituída com base em três categorias de 2a ordem: "Ignora a dor", "Desvalorização" e "Esquece", que interpretamos como quase um mecanismo de negação da sua existência. A segunda, "Estratégias para controle da dor", agrega as categorias de $2^{\mathrm{a}}$ ordem "Estratégias específicas de controle da dor" e "Estratégias inespecíficas de controle da dor" expressando uma preocupação de circunscrever a perceção da dor a uma dimensão controlada e suportável. Por fim, a última categoria de $1^{\mathrm{a}}$ ordem ressalta a "Frustração associada à dor" que, tendo menos referências que as categorias anteriores, dá nota de que apesar dos vários esforços despendidos, a dor existe e é no mínimo incômoda, porque faz parte do processo de treino diário.

Oportunamente distinguimos a dor do treino regular, da dor que advém da lesão sempre temida, porque tem implicações que a dor do treino não tem. Focados nesta diferenciação encontramos na Tabela 3 a hierarquização categorial obtida após análise das respostas à questão Como é que descreve a sua experiência de ser bailarino e ter que "conviver" com as lesões? 
Tabela 2. Categorias de $1^{\text {a }}$ e $2^{\text {a }}$ ordem obtidas na questão "No seu caso, como é que lida com a dor/desconforto físico que pode estar presente no treino diário?"

\begin{tabular}{|c|c|c|}
\hline Unidades de análise & $\begin{array}{l}\text { Categorias de } 2^{\text {a }} \\
\text { ordem }\end{array}$ & $\begin{array}{l}\text { Categorias de } 1^{\text {a }} \\
\text { ordem }\end{array}$ \\
\hline $\begin{array}{l}\text { "Quando a dor é muito forte penso que é por um bom motivo" - suj. } \\
3 \\
\text { "É a dor que nos torna mais forte" - suj. } 3 \\
\text { "(A dor é) que nos incentiva a continuar para atingir a perfeição" - } \\
\text { suj. } 3 \\
\text { "É como um aliado para atingirmos os nossos objetivos" - suj. } 5 \\
\text { "Lembrando-me que vale a pena a dor por que passo"- suj. } 6 \\
\text { "(A dor) vale sempre a pena" - suj. } 10\end{array}$ & $\begin{array}{l}\text { Vê a dor como } \\
\text { aliada } \\
(\mathrm{N}=4 \text {; Ref. }=6)\end{array}$ & $\begin{array}{l}\text { A dor como } \\
\text { aliada da dança } \\
\text { clássica } \\
(\mathrm{N}=7 \text {; Ref. }=17)\end{array}$ \\
\hline $\begin{array}{l}\text { "Normalmente lido bem com a dor do treino" - suj. } 1 \\
\text { "Acho uma dor confortável na maior parte das vezes" - suj. } 1 \\
\text { "Arde no sentido de esticar e isso dá uma sensação de conforto pelo } \\
\text { alongamento" - suj. } 1 \\
\text { "É como se o músculo estivesse relaxado numa contração" - suj. } 1 \\
\text { "Tento lidar de uma forma positiva" - suj. } 9 \\
\text { "É algo que o bailarino tem que saber lidar" - suj. } 9\end{array}$ & $\begin{array}{l}\text { A dor é interpretada } \\
\text { de forma positiva } \\
(\mathrm{N}=2 \text {, Ref. }=6)\end{array}$ & \\
\hline $\begin{array}{l}\text { "Tem que saber aceitar a dor" - suj. } 9 \\
\text { "Eu aceito a dor" - suj. } 10 \\
\text { "Eu aceito o desconforto" - suj. } 10\end{array}$ & $\begin{array}{l}\text { Aceitação da dor } \\
(\mathrm{N}=2 \text {; Ref. }=3)\end{array}$ & \\
\hline $\begin{array}{l}\text { "A dor torna-se algo natural" - suj. } 5 \\
\text { "Para mim é normal" - suj. } 8\end{array}$ & $\begin{array}{l}\text { Dor natural } \\
(\mathrm{N}=2 \text {; Ref. }=2)\end{array}$ & \\
\hline $\begin{array}{l}\text { "Às vezes ignoro" - suj. } 2 \\
\text { "Por vezes tento não pensar nisso" - suj. } 3 \\
\text { "Abstraio-me com a música" - suj. } 3 \\
\text { "(Abstraio-me) com a coreografia" - suj. } 3 \\
\text { "(Abstraio-me) com as outras colegas" - suj. } 3 \\
\text { "Quando estou no palco olho para a frente, fecho os olhos e depois } \\
\text { encaro o público a sorrir e a dor "passa" - suj. } 3 \\
\text { "Só paro em último recurso" - suj. } 9\end{array}$ & $\begin{array}{l}\text { Ignora a dor } \\
(\mathrm{N}=3 \text {; Ref. }=7)\end{array}$ & $\begin{array}{l}\text { A dor ignora-se e } \\
\text { ultrapassa-se } \\
(\mathrm{N}=6 \text {; Ref. }=12)\end{array}$ \\
\hline $\begin{array}{l}\text { “Quando se gosta realmente a dor não é nada” - suj. } 6 \\
\text { "E penso que 'não há de ser nada”" - suj. } 8 \\
\text { "Penso que 'há-de passar"”- suj. } 8\end{array}$ & $\begin{array}{l}\text { Desvalorização } \\
(\mathrm{N}=2 ; \text { Ref. }=3)\end{array}$ & \\
\hline $\begin{array}{l}\text { "Decorrer da aula por vezes até se esquece" - suj. } 7 \\
\text { "A dor está lá sempre mas tem-se que esquecer" - suj. } 7\end{array}$ & $\begin{array}{l}\text { Esquece } \\
(\mathrm{N}=1 ; \text { Ref. }=2)\end{array}$ & \\
\hline $\begin{array}{l}\text { "Não faço os exercícios tão aprofundados" - suj. } 2 \\
\text { "No momento da dor mais forte tento controlar a respiração" - suj. } 4 \\
\text { "(Tento) não focar na dor" - suj. } 4 \\
\text { "Alternativas ao tratamento farmacológico" - suj. } 4 \\
\text { "Quando estou com dor faço mais devagar" - suj. } 8 \\
\text { "Não forço tanto para não massacrar a zona" - suj. } 8 \\
\text { "Saber parar para não fazer piorar a lesão" - suj. } 9\end{array}$ & $\begin{array}{l}\text { Estratégias } \\
\text { específicas de } \\
\text { controle da dor } \\
(\mathrm{N}=4 \text {; Ref. }=7)\end{array}$ & $\begin{array}{l}\text { Estratégias para } \\
\text { controle da dor } \\
(\mathrm{N}=4 \text {; Ref. }=9)\end{array}$ \\
\hline $\begin{array}{l}\text { "Aprendendo quais os meus limites" - suj. } 4 \\
\text { "(Aprendendo) Como devo proteger o meu corpo dessas lesões" - } \\
\text { suj. } 4\end{array}$ & $\begin{array}{l}\text { Estratégias } \\
\text { inespecíficas de } \\
\text { controle da dor } \\
(\mathrm{N}=1 \text {; Ref. }=2)\end{array}$ & \\
\hline $\begin{array}{l}\text { "Às vezes é muito difícil" - suj. } 9 \\
\text { "Quando a dor é em demasia pode provocar frustação" - suj. } 9 \\
\text { "Não conseguirmos chegar aos } 100 \% \text { naquele ensaio" - suj. } 9 \\
\text { "É frustante depois querer fazer e não conseguir" - } 10 \\
\text { "É frustante" - suj. } 10 \\
\text { "Chega a um ponto que nem me sinto bem comigo própria" - suj. } 10 \\
\text { "Quando não consigo a dar o meu melhor" - suj. } 10 \\
\text { "Existem dores que não se aguenta o ensaio todo"- suj.10 }\end{array}$ & $\begin{array}{l}\text { Frustração } \\
\text { associada à dor } \\
(\mathrm{N}=2 \text {; Ref. }=8)\end{array}$ & $\begin{array}{l}\text { Frustração } \\
\text { associada à dor } \\
(\mathrm{N}=2 ; \operatorname{Ref}=8)\end{array}$ \\
\hline
\end{tabular}


Tabela 3. Categorias de $1^{\mathrm{a}}$ e $2^{\mathrm{a}}$ ordem obtidas na questão "Como é que descreve a sua experiência de ser bailarino e ter que 'conviver' com as lesões?".

\begin{tabular}{|c|c|c|}
\hline Unidades de análise & $\begin{array}{l}\text { Categorias de } 2^{\text {a }} \\
\text { ordem }\end{array}$ & $\begin{array}{c}\text { Categorias de } \\
1^{\text {a }} \text { ordem }\end{array}$ \\
\hline $\begin{array}{l}\text { "Uma lesão tem um impacto não só físico mas emocional" - suj. } 1 \\
\text { "Nada que uma boa pomada não cure (Voltaren)" - suj. } 2 \\
\text { "Por vezes as recuperações são dolorosas a nivel fisico"- suj. } 9 \\
\text { "(As recuperações são dolorosas) a nível mental" - suj.9 } \\
\text { "Quando me lesiono e é grave recorro a um fisioterapeuta" - suj. } 10 \\
\text { "Para tratar e ter consciência se posso dançar com calma ou se tenho que } \\
\text { parar durante algum tempo" - suj. } 10\end{array}$ & $\begin{array}{l}\text { Recuperações das } \\
\text { lesões } \\
(\mathrm{N}=4 \text {; Ref. }=6)\end{array}$ & $\begin{array}{l}\text { Estratégias } \\
\text { de confronto } \\
\text { com a lesão e a } \\
\text { recuperação } \\
(\mathrm{N}=5 \\
\text { Ref. }=11)\end{array}$ \\
\hline $\begin{array}{l}\text { "Aprender a conviver com elas"- suj. } 4 \\
\text { "Não deixar que a lesão se apodere de toda a nossa vida"- suj. } 4 \\
\text { "Aprender a lidar com as lesões"- suj. } 4 \\
\text { "É necessário ter maturidade" - suj. } 4 \\
\text { "(É necessário) enfrentar a dor de uma forma mais tranquila - suj. } 4\end{array}$ & $\begin{array}{l}\text { Aprendizagem } \\
\text { para lidar com a } \\
\text { lesão } \\
(\mathrm{N}=1 ; \text { Ref. }=5)\end{array}$ & \\
\hline $\begin{array}{l}\text { "É uma coisa que levo a sério" - suj. } 1 \\
\text { "Gosto muito" - suj. } 1 \\
\text { "A experiência de ser bailarina é única" - suj. } 3 \\
\text { "Para quem realmente gosta de dança" - suj. } 3 \\
\text { "A dança é um sonho" - suj. } 3 \\
\text { "Eu sinto-me completamente viciada em dança" - suj. } 3 \\
\text { "Gosto de dançar" - suj. } 3 \\
\text { "Agradeço todos os dias a possibilidade de dançar" - suj. } 3\end{array}$ & $\begin{array}{l}\text { Dança como } \\
\text { paixão } \\
(\mathrm{N}=2 ; \text { Ref. }=8)\end{array}$ & $\begin{array}{l}\text { Reafirmação } \\
\text { da emoção } \\
\text { e da paixão } \\
\text { associadas à } \\
\text { dança } \\
(\mathrm{N}=2 \text {; } \\
\text { Ref. }=10)\end{array}$ \\
\hline $\begin{array}{l}\text { "A dança causa emoções em nós" - suj. } 3 \\
\text { "(A dança causa emoções) também em quem nos vê" - suj. } 3\end{array}$ & $\begin{array}{l}\text { Dança como } \\
\text { emoção } \\
(\mathrm{N}=1 ; \text { Ref. }=2)\end{array}$ & \\
\hline $\begin{array}{l}\text { "(As lesões) não são nada comparadas com a gratificação de ser } \\
\text { bailarina" } \\
\text { "É lutar com todas as forças para fazer todos os movimentos que são } \\
\text { exigidos" } \\
\text { "Tive que ultrapassar para provar que podia ser uma grande bailarina" - } \\
\text { (todas as anteriores do suj. 3) } \\
\text { "Para mim já é "normal" se tiver uma lesão" - suj. } 9\end{array}$ & $\begin{array}{l}\text { Lesão como } \\
\text { condição para ser } \\
\text { bailarina } \\
(\mathrm{N}=2 \text {; Ref. }=4)\end{array}$ & $\begin{array}{l}\text { Lesão como } \\
\text { experiência } \\
\text { habitual e } \\
\text { inerente à } \\
\text { prática da dança } \\
(\mathrm{N}=4 \text {; Ref. }=9)\end{array}$ \\
\hline $\begin{array}{l}\text { "Experiência difícil" - suj. } 6 \\
\text { "É muito complicado" - suj. } 10 \\
\text { "São alguns pequenos obstáculos" - suj. } 3 \\
\text { "A partir de uma certa idade já nos é mais fácil saber lidar" - suj. } 4 \\
\text { "Acabamos por nos conseguirmos habituar a essa dor constante" - suj. } 6\end{array}$ & $\begin{array}{l}\text { Experiência de } \\
\text { ter lesões } \\
(\mathrm{N}=3 \text {; Ref. }=3) \\
\text { Lesões como } \\
\text { hábito }(\mathrm{N}=2 \text {; } \\
\text { Ref. }=2)\end{array}$ & \\
\hline $\begin{array}{l}\text { "Leva-me a questionar o futuro" - suj. } 1 \\
\text { "Medo que alguma lesão dê literalmente cabo de mim" - suj } 8 \\
\text { "(Medo) de me dizerem que não posso práticar mais ballet" - suj. } 8 \\
\text { "E não poder dançar mais" - suj. } 8 \\
\text { "(Não consigo imaginar) acabar com a minha vida de bailarina" - suj. } 10\end{array}$ & $\begin{array}{l}\text { Medo da lesão } \\
\text { como fim da } \\
\text { prática do ballet } \\
(\mathrm{N}=3 ; \text { Ref. }=5)\end{array}$ & $\begin{array}{l}\text { Medo } \\
(\mathrm{N}=3 ; \text { Ref. }=8)\end{array}$ \\
\hline $\begin{array}{l}\text { "Medo" - suj. } 8 \\
\text { "Medo de que alguma delas me dê uma dor tão forte" - suj. } 8 \\
\text { "Não consigo imaginar ter uma lesão" - suj. } 10\end{array}$ & $\begin{array}{l}\text { Lesão e medo } \\
\text { inespecífico } \\
(\mathrm{N}=2 ; \text { Ref. }=3)\end{array}$ & \\
\hline $\begin{array}{l}\text { "O ideal é proteger sempre o nosso corpo para evitar lesões" - suj. } 9 \\
\text { "Tento proteger o meu corpo de forma a não forçar demasiado onde } \\
\text { tenho dores repetidas e intensas" - suj.9 } \\
\text { "Resguardo-me do frio para nao criar contraturas" - suj.9 } \\
\text { "Resguardo-me do frio para não ter dores nas articulações" - suj. } 9 \\
\text { "Fazer piscina faz muito bem aos músculos" - suj. } 9 \\
\text { "Temos que ter o dobro do cuidado para não nos magoarmos" - suj. } 9\end{array}$ & $\begin{array}{l}\text { Estratégias de } \\
\text { prevenção da } \\
\text { lesão } \\
(\mathrm{N}=1 ; \text { Ref. }=6)\end{array}$ & $\begin{array}{l}\text { Estratégias de } \\
\text { prevenção da } \\
\text { lesão } \\
(\mathrm{N}=1 \text {; Ref. = 6) }\end{array}$ \\
\hline
\end{tabular}


Tal como realizado com as respostas do grupo à pergunta anterior apresentamos aquela que poderia ser a resposta global a esta questão que versa sobre a dor inerente às lesões.

Assim, a experiência das bailarinas entrevistadas pressupõe estratégias de confronto e de recuperação das ocorrências que surgem de forma regular e inerentes à paixão e à emoção provocadas pela dança, mas das quais têm tanto medo que mais vale as prevenir.

Mais detalhadamente, encontramos cinco categorias de significado de $1^{\text {a }}$ ordem que sintetizam como é que as participantes lidam com o fato de surgirem lesões no decorrer dos seus percursos.

Maioritariamente referem "Estratégias de confronto com a lesão e a recuperação", categoria de $1^{\text {a }}$ ordem com mais peso (quanto ao número de referências) que resulta de duas categorias hierarquizadas de $2^{\text {a }}$ ordem: "Recuperação das lesões" e "Aprendizagem para lidar com a lesão". Expressam uma consciência clara da necessidade de ter competências para enfrentar os incidentes que pautam a prática de uma atividade vivida com muita intensidade afetiva, transparente na categoria central "Reafirmação da emoção e da paixão associadas à dança", que agrega os testemunhos que veem a "Dança como paixão" e a "Dança como emoção". A seguinte categoria de $1^{\text {a }}$ ordem, "Lesão como experiência habitual e inerente à prática da dança", tem na sua origem as categorias de 2a ordem - "Lesão como condição para ser bailarina", "Experiência de ter lesões" e "Lesões como hábito" - que espelham uma presença da dor banalizada na vivência e experiência da dança. Contudo, há quem dela tenha "Medo" e, nesta categoria central conjugam-se duas categorias de 2a ordem: "Medo da lesão como fim da prática do ballet" e "Lesão e medo inespecífico". Encontramos claras referências a um medo vago, mas também indicações de um fantasma maior associado ao fim da possibilidade de dançar, pelo que não estranhamos que as "Estratégias de prevenção da lesão" constituam a última categoria central.

Interessantemente, em mais de 40 unidades de análise a dor só é assinalada 4 vezes por 3 das bailarinas, quando a temática nuclear da questão é o convívio com as lesões.

Esta constatação leva-nos a considerar a possibilidade de a dor estar integrada no treino diário e não tão associada à lesão, que surge com um significado possivelmente mais ameaçador e menos controlado que a experiência dolorosa rotineira.

\section{Discussão}

Da análise dos discursos recolhidos podemos inferir que a associação entre o ballet e a dor se apresenta como uma experiência com um alto grau de subjetividade, dependendo de aspetos fisiológicos, emocionais e da história pessoal do sujeito, sendo definida como uma experiência sensorial e emocional desagradável associada com efetiva ou potencial lesão de tecidos, ou descrita em termos dessa lesão (International Association for Study of Pain). Nesta linha, e para Pollard-Smith e Thomson ${ }^{9}$, o desenvolvimento pessoal de cada bailarino resulta de uma amálgama de pressões internas e externas.

Os dados obtidos confirmaram que a aparente leveza do ballet contrasta com os sintomas dolorosos associados à sua prática e que têm sido objeto de crescente investigação nos últimos anos. Sendo o ballet clássico uma atividade de alta performance e elevado nível técnico compreendemos que nos discursos recolhidos transpareça a perspetiva de que a dor é uma presença indissociável da performance e do treino, podendo inclusivamente tornar-se um fator de crescimento no percurso técnico a ser feito, quando se assume como natural ou até positiva, mas que existe um outro lado da moeda, em que a dor se ignora, esquece, ou seja, se nega. Foi a esta relação que denominamos como "dor aliada da dança". Interessantemente, a palavra sofrimento não surgiu uma única vez nas unidades discursivas recolhidas nas 10 entrevistas, uma vez que para um bailarino a dor física não é sinónimo de sofrimento, pois se a experiência da dor é um facto, o sofrimento por causa dela já é subjetivo, e não é automático. Em certa medida resulta de uma escolha, para a qual se prepararam, a par da preparação do seu controle anatômico.

Na ligação tácita da dor à dança estão as lesões, e a preparação, já referida, não garante que não ocorram, não só como consequências de traumatismos inesperados, mas também como efeito de um trabalho excessivo, persistente e em fases muito delicadas do desenvolvimento.

Os bailarinos estão em permanente risco de romper as barreiras da sua maleabilidade, contudo, silenciam o corpo, tendem a tratá-lo como um objeto controlado somente pela mente, pelo que são altamente seletivos sobre onde devem colocar o seu foco em termos da experiência das sensações físicas ${ }^{10}$. A este respeito Pollard-Smith e Thomson ${ }^{9}$ referem que, mais do que refletir sobre a sua experiência, os jovens dançarinos experienciam o seu corpo e os seus movimen- 
tos. Faz, pois, sentido que as 10 participantes integrem as lesões na sua experiência de dançar como parte do processo, desvalorizando-as e esvaziando-as de significados que possam ir para além da aprendizagem e da sinalização da paixão pela dança, de encontro às referências que reconhecem que os processos dolorosos envolvidos no processo são percebidos como necessários, e que ultrapassá-los é sinal de valentia e de cumprimento do dever ${ }^{7}$. Porém, surgem pequenas lesões que se acabam por transformar em sérias e graves ${ }^{4}$. Assim, por muito motivada que uma bailarina esteja e por muito que treine, quando se lesiona o sucesso do seu projeto profissional fica comprometido. Por isso se justifica nos discursos recolhidos o aparecimento do "medo", não associado à dor inerente à prática e treino da dança ( $1^{\mathrm{a}}$ questão), mas sim às lesões e ao potencial limitativo que acarretam no presente e essencialmente no futuro das suas carreiras ( $2^{\mathrm{a}}$ questão $)^{4}$. Interessantemente surgem duas categorias de primeira ordem que visam quer a prevenção quer a recuperação da lesão. No primeiro caso as unidades discursivas apontam na generalidade para práticas banais e até pouco específicas. No segundo caso, relacionado com o tratamento das lesões aparece a temática da aprendizagem com a lesão a par de estratégias indefinidas em termos terapêuticos, o que vai de encontro à opinião de Pollard-Smith e Thomson', quando referem que pouco se sabe sobre a procura de tratamento por parte dos bailarinos, bem como da investigação epidemiológica quantitativa sobre as lesões relacionadas com a dança, ressaltando ao mesmo tempo que são as pressões internas e externas acima referidas que quando combinadas com experiências de dor e lesão determinam a capacidade do bailarino ter estratégias de confronto com a dor, tomar decisões e procurar tratamento. Uma referência possível nesta discussão seria a do trabalho de Christophe Dejours abordado por Araújo e Rolo quando referem: "Assim, a negação e/ou o não reconhecimento da realidade do trabalho duma pessoa pode ser fonte de sofrimento mental. Mas em contrapartida, o reconhecimento no trabalho é um elemento determinante da realização pessoal e contribui para a construção da identidade, sendo fonte de prazer no trabalho: a relação com os pares donde emerge o reconhecimento e a identidade de pertença a um coletivo" ${ }^{18}$. Esta associação à experienciação de dor e de prazer em contexto de trabalho, ao ser extrapolada para a prática do bailado, reforça a importância dos outros, nomeadamente dos parceiros de performance.
Finalmente a paixão pela dança “espreita” em múltiplas unidades discursivas recolhidas para ambas as perguntas. Tendo em linha de conta que a investigação qualitativa reconhece a individualidade das perspetivas dos participantes e as suas experiências da dor e da lesão permitindo explorá-las e compreendê-las de forma mais profunda e contextualizada ${ }^{19,20}$, nas vozes registadas encontramos narrativas de esforço, superação, sacrifício, frustração, mas também de paixão, numa perspetiva íntima e privada de partilha de significados que muitas vezes não se divisam nas performances perfeccionistas e apaixonadas das bailarinas clássicas.

Para a manutenção deste estado de apaixonamento contribuem os resultados artísticos, físicos e até as recompensas psicológicas que advêm da prática da dança. E haverá sentimento tão saturado de subjetividade quanto a paixão, mesmo quando dirigida para uma arte performativa de alta exigência? Apesar de não se tratarem de bailarinas profissionais, eventual limite do estudo, da análise qualitativa realizada sobressai a paixão pela dança como música de fundo, onde as vozes das bailarinas participantes permitiram o acesso a várias dimensões que conferem significados múltiplos ao contínuo da dor, significados tais como desvalorizada, negada, ou usada como alavanca para continuar ${ }^{7}$.

\section{Conclusão}

Esta investigação teve como fim compreender os significados associados à dor na performance das bailarinas clássicas, num registo expectável de subjetividade, complexidade e diversidade, razões pelas quais utilizamos o método proposto pela Grounded Theory, procedendo à recolha, registo, transcrição, organização, interpretação, estudo e construção hierarquizada da informação obtida.

$O$ recurso à recolha da informação via online mostrou-se eficaz na colheita dos discursos e uma mais valia na gestão do tempo e disponibilidade das participantes, num registo que vai além das barreiras sociais e culturais, ao mesmo tempo que encorajam os sujeitos a partilhar mais sobre $\mathbf{s i}^{21}$. Por outro lado, Gray e Kunkel ${ }^{22}$, assinam a única referência que encontramos associando a Grounded Theory e a experiência de bailarinas clássicas, sem que todavia a temática da dor emerja, e vai de encontro à nossa escolha metodológica quando nos focamos na experiência das 10 bailarinas e na sua vivência da dança e da dor. 
Como limitações do estudo desenvolvido reconhecemos a desinserção das duas questões analisadas do conjunto global constituído pelas restantes 7 , que provavelmente facilitariam uma compreensão mais integrada, bem como o facto de a amostra ser apenas constituída por elementos femininos. Pensamos que a consideração da experiência de bailarinos do sexo masculino que têm funções diferentes na performance do ballet clássico poderá ser uma mais-valia interessante. Reconhecemos que, a par das vantagens da realização das entrevistas via online, algumas desvantagens podem ocorrer, nomeadamente no que respeita à ausência da componente não verbal, enquanto elemento primordial do processo de comunicação interpessoal.

Terminamos este artigo com a noção de que uma dimensão de grande relevo e indiretamen- te ligada ao esforço das bailarinas ficou por explorar. A dimensão em causa é a que suporta a procura de um corpo perfeito, enquanto instrumento de maleabilidade, leveza e perfeição. Este corpo, nomeado pela literatura como "corpo Balanchine", está na mente da maioria das bailarinas e significa sacrifício, dor, fome, entre outras coisa $^{23}$. Esta será pois a nossa futura preocupação, enquanto fonte de interesse para aprofundamento da presente investigação.

Com a consciência de que a subcultura do ballet tem as suas regras de funcionamento, nomeadamente no que diz respeito à gestão do sofrimento físico, pensamos ter trazido alguma luz às experiências subjetivas de bailarinas clássicas, e à sua vivência individual desta forma de arte que também tem muito de desporto de elite 5 .

\section{Colaboradores}

C Costa - construção dos instrumentos, realização das entrevistas, recolha dos dados, análise e categorização dos dados e escrita do presente artigo. Z Teixeira - construção dos instrumentos, recolha dos dados, análise e categorização dos dados e escrita do presente artigo. 


\section{Referências}

1. Forte M. An intricate intimacy: ethics in the dance studio. The dance current 2010; 12(9):34-44.

2. Wainwright SP, Williams C, Turner BS. Fractured Identities: injury and the balletic body. Health (London) 2005; 9(1):49-66.

3. Almeida D, Flores-Pereira M. As Corporalidades do Trabalho Bailarino: Entre a Exigência Extrema e o Dançar com a Alma. RAC 2013; 17(6):720-738.

4. Murgia C. Overuse, tissue fatigue, and injuries. J Dance Med. Sci. 2013; 17(3):92-100.

5. McEwen K, Young K. Ballet and pain: reflections on a risk - dance culture. Qualitative research in sport, exercise and health 2011;3(2):152-173.

6. Batista C, Martins E. A prevalência de dor em bailarinas clássicas. Health Sci Inst 2010; 28(1):47-49.

7. Costa C, Teixeira Z. "Pas de Deux" com a Dor: Vozes da experiência de bailarinas de dança clássica. Atas CIAIQ 2017; Volume 2. [acessado 2018 Jan 4]. Disponível em: http://proceedings.ciaiq.org/index.php/ciaiq2017/article/view/1499/1456

8. Thomas H, Tarr J. Dancers Perceptions of Pain and Injury: Positive and Negative Effects. Journal of Dance Medicine and Science 2009; 13(2):51-59.

9. Pollard-Smith T, Thomson OP. Professional ballet dancers' experience of injury and osteopathic treatment in the UK: A qualitative study. Journal of bodywork and movement therapies 2017; 21(1):148-156.

10. Aalten A. In the Presence of the Body: Theorizing, Training, Injuries and Pain in Ballet. Dance Research Journal 2005; 37(2):57-72.

11. Denzin NK, Lincoln YS. The discipline and practice of qualitative research. London: Sage Publications; 2000.

12. Field U. Mapping the field. London: Sage; 2014.

13. Charmaz K. Constructing Grounded Theory. Thousand Oaks: SAGE Publications; 2014.

14. Hołyst JA. Introduction to Cyberemotions. In: Holyst JA. Cyberemotions. Berlin: Springer; 2017. p. 1-7.

15. Blöbaum B. Trust and communication in a digitized world: models and concepts of trust reserarch. Munique: Springer International Publishing; 2016.
16. Reips U-D. How internet-mediated research changes science. In: Barak A. Psychological aspects of cyberspace: Theory, research, applications. Cambridge: University Press; 2014. p. 268-294.

17. Strauss A, Corbin JM. Basics of qualitative research: Grounded theory procedures and techniques. Newbury Park: SAGE Publications; 1990.

18. Araújo C, Rolo D. Apresentação do Dossier Temático: Psicodinâmica e Psicopatologia do trabalho. Laboreal 2011; 7(1):10-12.

19. Petty NJ, Thomson OP, Stew G. Ready for a paradigm shift? Part 1: introducing the philosophy of qualitative research. Man Ther 2012; 17(4):267-274.

20. Petty NJ, Thomson OP, Stew G. Ready for a paradigm shift? Part 2: introducing qualitative research methodologies and methods. Man Ther 2012; 17(5):378-384

21. Joinson A, Reips U, Buchanan T, Schofield C. Privacy, Trust, and Self-Disclosure Online. Human-Computer Interaction 2010; 25:1-24.

22. Gray MK, Kunkel MA. The experience of female ballet dancers: a grounded theory. High Ability Studies 2001; 12(1):7-25.

23. Kiem E. Dancer, Daughter, Traitor, Spy. 2013. [acessado 2017 Dez 28]. Disponível em: http://www.huffingtonpost.com/elizabeth-kiem/post_6717_b_4640946. $\mathrm{html}$

Artigo apresentado em 02/04/2018

Aprovado em 22/10/2018

Versão final apresentada em 19/02/2019 
